\title{
Ultrasonic Testing of Artificial Defects in Alumina Ceramic
}

\author{
Li-Shin Chang* \& Tung-Han Chuang \\ Institute of Materials Science and Engineering, National Taiwan University, Taipei, Taiwan
}

(Received 1 November 1995; accepted 18 January 1996)

\begin{abstract}
This research tried to correlate the defect diameter and the ultrasonic signal reflected from the interface between an alumina matrix and artificial cylinder-like defects. Some fundamental acoustic and geometrical equations were used to determine the diameter from some known or pre-measured parameters. A final comparison between the real and predicted defect diameter was made to check out the accuracy of the model. The error of the size prediction of a solid defect was smaller than $65 \%$ in $10 \mathrm{MHz}$ ultrasonic testing and even smaller than $15 \%$ when the defect type was a hole. The influence of the defect diameter on the prediction was dependent on the shrinkage of the specimens. We also found that the best density for ultrasonic testing was around $3.8 \mathrm{gm} / \mathrm{cm}^{3}$. (C) 1997 Elsevier Science Limited and Techna S.r.l.
\end{abstract}

Keywords: alumina, ultrasonic testing, artificial defects.

\section{INTRODUCTION}

Ceramics are usually very sensitive to cracks because of their poor toughness. Therefore, unreliable specimen preparation may violently change the properties of ceramics. Non-destructive testing (NDT) methods can avoid most of the disadvantages of destructive testing, and especially ultrasonic testing (UT) has received the most attention in the last few years. ${ }^{1,2}$ Not only is it economical and reliable, but it also has a large field of application, a wide range of detectable defect types and strong penetration ability. In the applicability of ultrasonic testing on flaw defects, Sokolov in 1929 measured the reduction of the echo intensity to identify the location of defects. In 1942, Firestone applied the ultrasonic technique, used in locating ships and measuring ocean depths, to materials. After 1945, most of the applications on metallic materials, for example, measurements of sound velocity, thickness, defects, mechanical properties, etc., were standardized. However, there has been little research on ceramics because of the difficulty in

*Present address: Institut für Metallkunde, Universität Stuttgart, Seestr. 75, 70174, Stuttgart, Germany producing the standard specimens. $\mathrm{Kino}^{3}$ has estimated defects in ceramics using high frequency UT. Khuri-Yakub et al. ${ }^{4}$ have used acoustic surface waves to measure surface cracks in ceramics. Hefetz and Rokhlin ${ }^{5}$ have also estimated thermal shock damage by using ultrasonic waves to detect surface microcracks. In this research, we placed some wires into alumina and then found the relation between the ultrasonic signal, especially that reflected by the intrinsic defects, and the actual defect size which was observed by cutting open the specimens.

\section{EXPERIMENTAL PROCEDURE}

\subsection{The preparation of alumina samples}

Platinum and nylon wires with diameters of 100 , 300 and $500 \mu \mathrm{m}$ as cylinder-like defects were put into ceramic disks while they were being formed from alumina slurry by pressure slip casting in two steps, which means that at first we cast only half of the slurry, poured out another half slurry from the mould, put the wire on the surface of the half cake, and then continued to cast the other half of the 


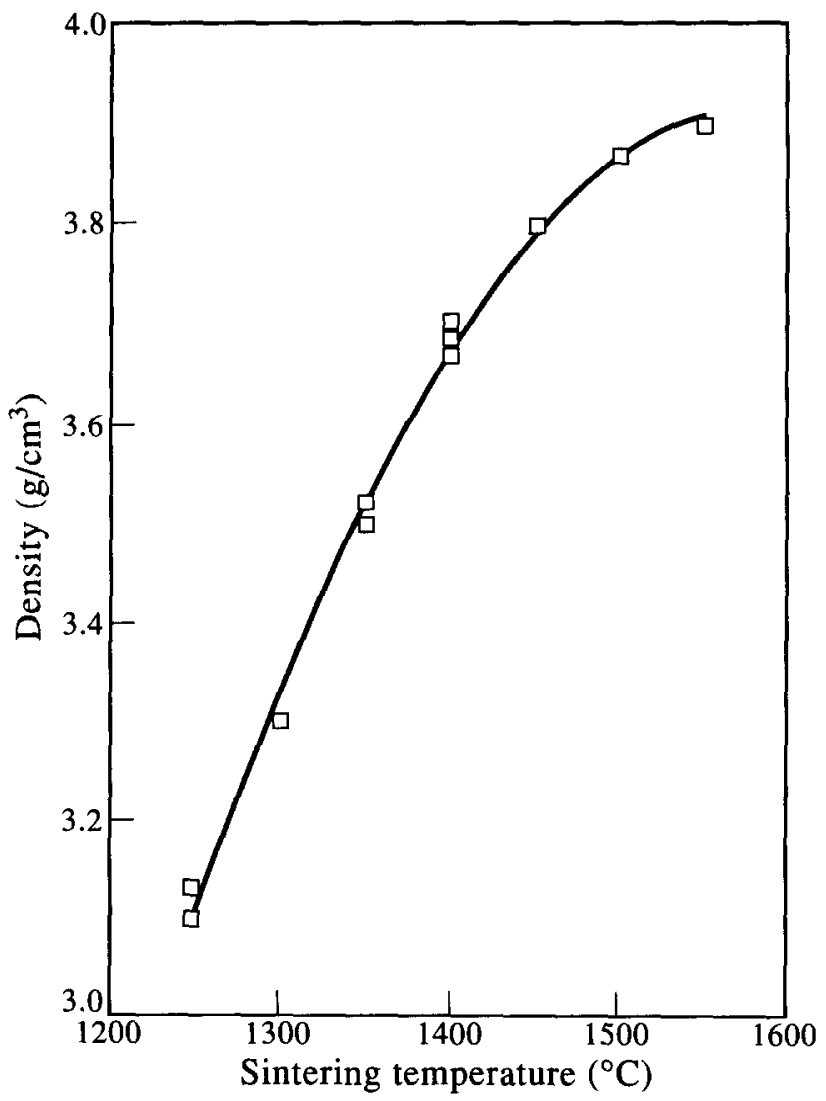

Fig. 1. The curve of densities related to sintering temperatures.

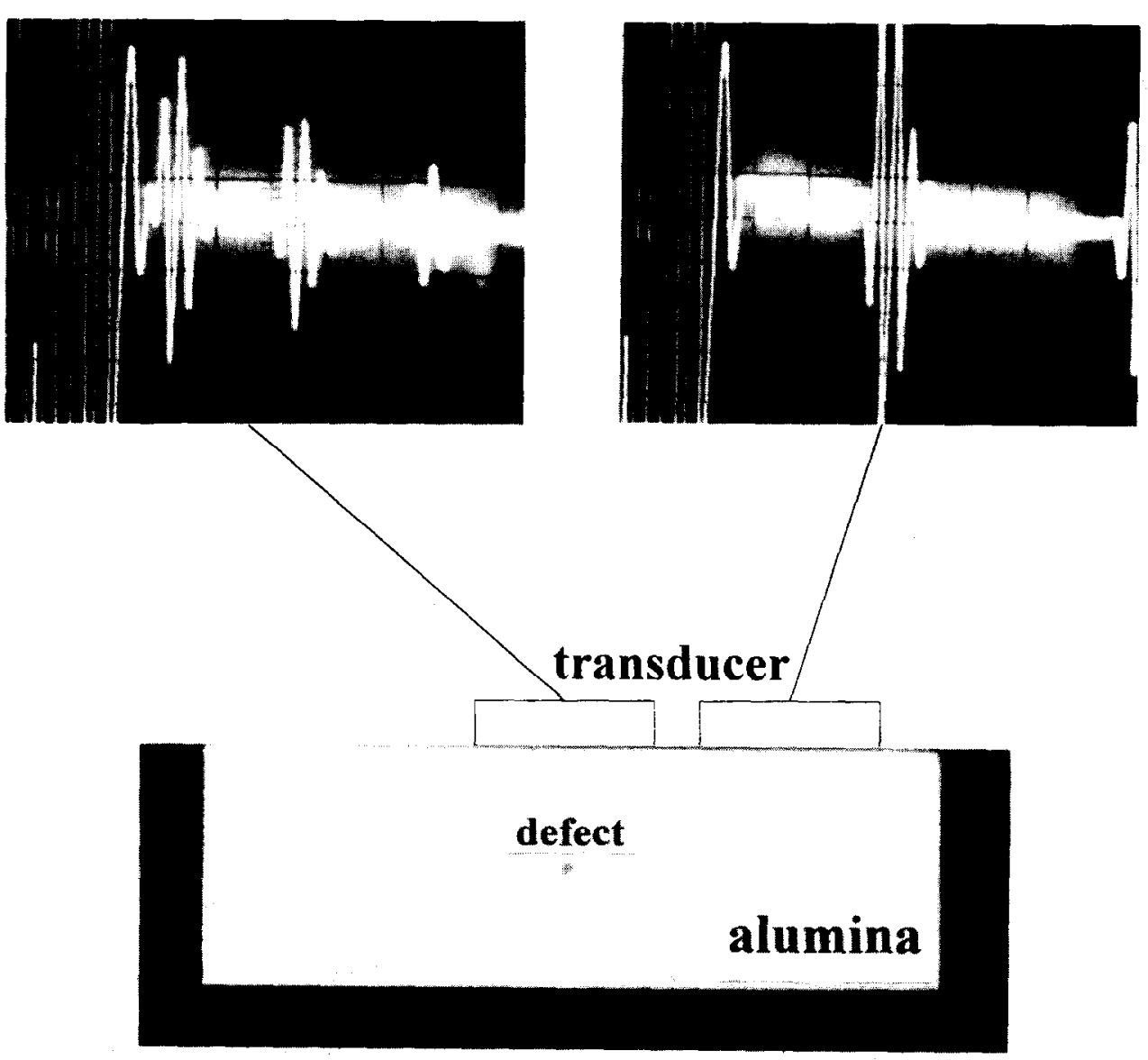

Fig. 2. Ultrasonic signals and their relative position in a specimen.

\subsection{The ultrasonic testing of alumina}

slurry until all of the slurry was cast. The slurry consisted of $50 \mathrm{wt} \% \mathrm{Al}_{2} \mathrm{O}_{3}$ powder and $0.5 \mathrm{wt} \%$ Darvan $\mathrm{C}$ as dispersant and binder. The duration of forming was $30 \mathrm{~min}$. under a uniaxial pressure of $10 \mathrm{~kg} / \mathrm{cm}^{2}$ when $20 \mathrm{ml}$ slurry was cast. The diameters of the green cakes were $25 \mathrm{~mm}$. The thickness of the green cakes was $10 \mathrm{~mm}$. After $24 \mathrm{~h}$ of drying at $60^{\circ} \mathrm{C}$, these green cakes were then sintered in air under temperatures of 1250,1350 , 1450 and $1550^{\circ} \mathrm{C}$ for $2 \mathrm{~h}$ to produce ceramics with different densities, as shown in Fig. 1. These bulk densities were measured by means of the Archimedes method. ${ }^{6}$ The sintered ceramic specimens were finally ground using a $500 \#$ diamond grinding wheel with a grinding rate of $0.02-0.04 \mathrm{~mm} /$ cycle.

The adopted ultrasonic testing equipment included a USIP 12 and DTM 12 made by the Krautkramer-Branson Corp. The transducer was unfocused and contacted the surfaces of the specimens with a couplant. The mode of ultrasonic testing adopted in this work was the A-scan mode. All of these experimental conditions are set for the purpose of simplifying the model for predicting the wire 
diameter. We chose $10 \mathrm{MHz}$ as the testing frequency and glycerine as the couplant. Two parameters, (1) the time difference between two echoes $(\Delta t)$ and (2) the amplitudes of the back echoes $\left(P_{\mathrm{b}}\right)$ and defect echoes $\left(P_{\mathrm{d}}\right)$, were recorded. An example of ultrasonic signals and their relative positions in a specimen is shown in Fig. 2. To confirm the defect entirely within the testing area of the transducer, the maximum defect echo amplitude was recorded during movement of the transducer along the surface of the specimens. After ultrasonic testing, the specimens were cut along the cross-section of defects. The real defect diameters were measured directly from the observed embedded defects in the ceramics as shown in Fig. 3.

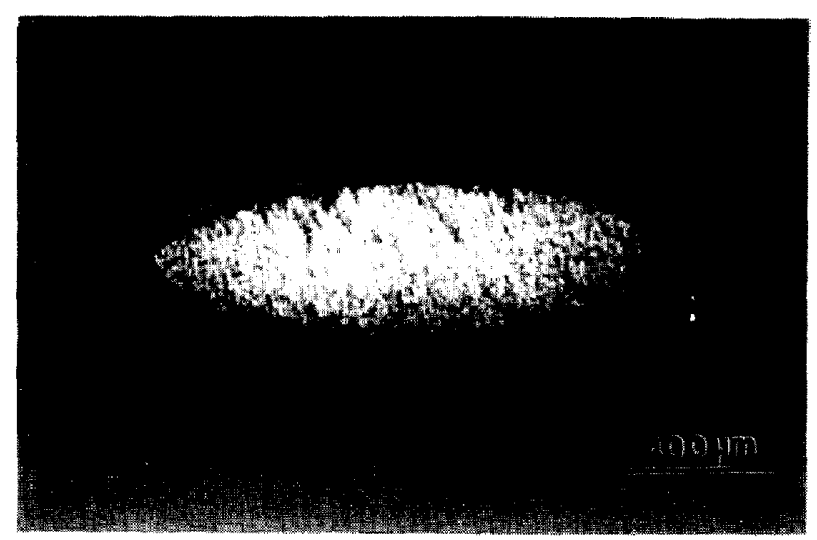

a.

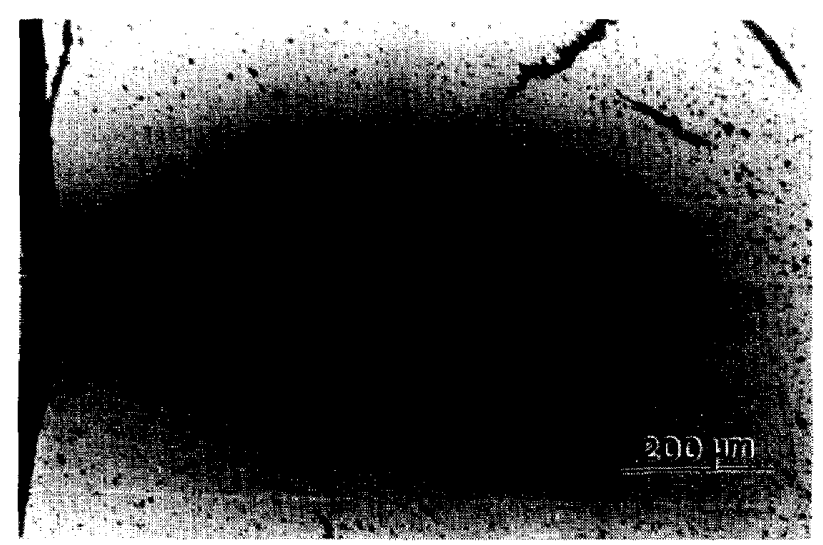

b.

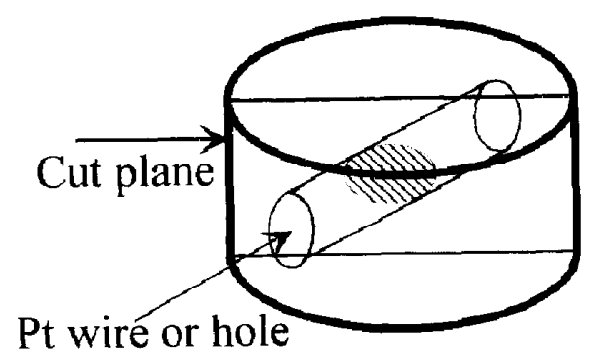

c.

Fig. 3. The cross-section of (a) the platinum wire; (b) the hole embedded in the alumina and (c) the schematic diagram.

\section{THEORY BACKGROUND}

A pulse is transmitted into the matrix, and a part of it is reflected from the curve interface on a defect. Besides the attenuation caused by scattering and absorption in grains and grain boundaries, ${ }^{7}$ there are several phenomena which need to be considered in estimating the cylinder's diameter from the echo amplitude. ${ }^{8}$ The description equations of these phenomena are presented as follows:

\subsection{Sound pressure $(P)$ at some point along the axis of the transducer. ${ }^{9}$}

$$
\begin{aligned}
P & =2 P_{0} \sin \left[\left(\sqrt{R^{2}+a^{2}}-a\right) \frac{\pi}{\lambda}\right] \\
& =k_{1} P_{0}
\end{aligned}
$$

where $P_{0}$ is the initial pressure, $R$ the transducer radius, $a$ the axial distance between the point and the transducer, and $\lambda$ the wavelength.

\subsection{Surface curvature effect of defects:}

$$
P=k_{1} P_{0} \sqrt{\frac{D}{2\left(1+\frac{x}{a}\right)\left[x+f\left(1+\frac{x}{a}\right)\right]}}=k_{1} k_{2} P_{0},
$$

where $a$ is the distance between the sound source and the curve surface, $x$ the distance between some point and the curve surface, and $D$ the defect diameter.

\subsection{Length of defects:}

$$
P=P_{0}\left[1-\left(\frac{2}{\pi} \cos ^{-1} \frac{L}{2 R}-\frac{L}{2 \pi R} \sqrt{1-\frac{L^{2}}{4 R^{2}}}\right)\right]=k_{3} P_{0}
$$

where $L$ is the defect length, $R$ the transducer radius and $k_{3}$ the effected area ratio.

\subsection{First reflection factor (I) in interfaces: ${ }^{10}$}

$$
\begin{gathered}
\text { from front interface } I_{1}=\frac{Z_{\mathrm{d}}-Z_{\mathrm{m}}}{Z_{\mathrm{d}}+Z_{\mathrm{m}}} \\
\text { from back interface } I_{2}=\frac{4 Z_{\mathrm{d}} Z_{\mathrm{m}}\left(Z_{\mathrm{d}}-Z_{\mathrm{m}}\right)}{\left(Z_{\mathrm{d}}+Z_{\mathrm{m}}\right)^{3}},
\end{gathered}
$$

where $Z_{\mathrm{d}}, Z_{\mathrm{m}}$ are the impedances of the defect and the matrix. It is notable that $I$ is very small and 
negligible after second reflection, and that the wave transformation which occurs by propagating through a non-flat interface is assumed to be negligible to simplify the model. The measured wavelength in the alumina at a frequency of $10 \mathrm{MHz}$ is about $100 \mu \mathrm{m}$, and the cylinder diameters are $n \times$ $100 \mu \mathrm{m}(n=1,3$ or 5$)$. That means the first reflections from the front and back interfaces have the same phase. The factor $\left(k_{4}\right)$ can be simply expressed by adding $I_{1}$ and $I_{2}$.

Combining all of these equations, the relation between the reflected sound pressure and initial pressure can be described as a function of defect diameter and defect depth:

$$
P=k_{1} k_{2} k_{3} k_{4} P_{0} e^{\alpha x}=f(D, x, \alpha) P_{0} .
$$

After measuring the defect depth $(x)$ which was calculated from $v \times \Delta t$ ( $v$ : sound velocity in specimen and $v=\frac{2 d}{\Delta t_{0}}$, $d$ : specimen thickness; $\Delta t_{0}$ : time difference between two back echoes from the bottom) and the attenuation coefficient $(\alpha)$, which was approximately calculated from $P_{\mathrm{b}}$, the cylinder diameter $(D)$ can be solved for when $P_{\mathrm{d}} / P_{\mathrm{b}}$ is known. As a comparison, we adopted the experience relation suitable for a cylinder hole:

$$
\frac{P_{\mathrm{d}}}{P_{0}}=\frac{k L \sqrt{D \lambda}}{2 \pi R^{2}},
$$

where $P_{\mathrm{d}}, P_{0}$ are the amplitudes of the defect echo and initial pulse, $L, D$ the length and diameter of the hole, $R$ the radius of the transducer, and $\lambda$ the wavelength.

\section{RESULTS AND DISCUSSION}

The wavelength, defect depth and attenuation coefficient measured from the pulse echoes and the defect diameters through ultrasonic determination and metallographic observation are summarized in Table 1. The defect diameter calculated from eqn (6) better matched the true value observed by using an optical microscope than did that from eqn (7). The error from the experience equation could be as much as $188 \%$. The errors from eqn (6) which we established were less than $65 \%$. Figure 4 shows that the influence of the defect type (solid or hole) was different with the same defect length. The prediction error of hole defects (made from nylon wire) decreased to the hole radius, while that of a solid defect embedded with platinum wire deceased firstly with defect size and then increased with a minimum at $D \approx 300 \mu \mathrm{m}$. This may be attributable to the residual stress region formed during sintering. At first, concerning the residual stress region, it is apparent to imagine that the accuracy of predicting the platinum radius should decrease with the density when a homogenous green cake was considered. But, in fact, the real correlation as shown in Fig. 5 is more complicated than that. The ideal consideration fitted only when the platinum radii were about $500 \mu \mathrm{m}$. The errors changed

\begin{tabular}{|c|c|c|c|c|c|c|c|c|c|c|c|c|}
\hline & No. & $\begin{array}{c}\lambda \\
(\mu \mathrm{m})\end{array}$ & $\underset{(\mu \mathrm{m})}{x}$ & $\begin{array}{c}\alpha \\
(\mathrm{Np} / \mu \mathrm{m})\end{array}$ & $\begin{array}{c}P_{\mathrm{d}} / P_{\mathrm{b}} \\
(\%)\end{array}$ & $\underset{(\mathrm{mm})}{L}$ & $\begin{array}{c}D_{0}^{*} \\
(\mu \mathrm{m})\end{array}$ & $\begin{array}{c}D_{1}^{*} \\
(\mu \mathrm{m})\end{array}$ & $\begin{array}{l}D_{2 a} a^{\circ} \\
(\mu \mathrm{m})\end{array}$ & $\begin{array}{l}D_{2 b}{ }^{\circ} \\
(\mu \mathrm{m})\end{array}$ & $\begin{array}{l}E_{2 \mathrm{a}}{ }^{\circ} \\
(\%)\end{array}$ & $\begin{array}{l}E_{2 \mathrm{~b}}{ }^{\circ} \\
(\%)\end{array}$ \\
\hline Hole & $\begin{array}{r}1 \\
2 \\
3 \\
4 \\
5 \\
6 \\
7 \\
8 \\
9 \\
10 \\
11 \\
12 \\
13 \\
14 \\
15 \\
16 \\
17 \\
18 \\
19 \\
20 \\
21 \\
22\end{array}$ & $\begin{array}{r}110 \\
109 \\
111 \\
106 \\
93 \\
69 \\
109 \\
90 \\
70 \\
108 \\
92 \\
68 \\
112 \\
113 \\
112 \\
111 \\
110 \\
111 \\
111 \\
111 \\
112 \\
112\end{array}$ & $\begin{array}{l}3409 \\
3550 \\
2962 \\
2002 \\
4005 \\
3533 \\
2890 \\
3252 \\
2973 \\
1973 \\
2600 \\
2632 \\
2517 \\
2270 \\
2067 \\
4807 \\
4417 \\
4065 \\
5249 \\
3887 \\
3736 \\
3517\end{array}$ & $\begin{array}{r}39 \\
51 \\
35 \\
41 \\
54 \\
45 \\
69 \\
58 \\
80 \\
18 \\
68 \\
102 \\
61 \\
53 \\
46 \\
34 \\
30 \\
24 \\
30 \\
29 \\
32 \\
36\end{array}$ & $\begin{array}{r}10.6 \\
6.4 \\
6.8 \\
4.4 \\
11.5 \\
21.1 \\
6.0 \\
10.0 \\
6.5 \\
3.0 \\
3.1 \\
2.8 \\
16.7 \\
15.0 \\
4.6 \\
7.7 \\
1.3 \\
15.7 \\
26.3 \\
4.6 \\
4.0 \\
4.5\end{array}$ & $\begin{array}{r}5 \\
5 \\
5 \\
5 \\
5 \\
5 \\
5 \\
5 \\
5 \\
5 \\
5 \\
5 \\
10 \\
10 \\
10 \\
3 \\
1 \\
5 \\
5 \\
5 \\
5 \\
5\end{array}$ & $\begin{array}{l}500 \\
300 \\
100 \\
500 \\
500 \\
500 \\
300 \\
300 \\
300 \\
100 \\
100 \\
100 \\
500 \\
300 \\
100 \\
500 \\
500 \\
500 \\
300 \\
100 \\
500 \\
500\end{array}$ & $\begin{array}{r}430 \\
280 \\
98 \\
430 \\
435 \\
430 \\
285 \\
285 \\
280 \\
96 \\
94 \\
98 \\
420 \\
285 \\
93 \\
435 \\
430 \\
350 \\
230 \\
98 \\
435 \\
430\end{array}$ & $\begin{array}{r}710 \\
282 \\
110 \\
484 \\
620 \\
556 \\
280 \\
230 \\
251 \\
78 \\
76 \\
40 \\
440 \\
236 \\
88 \\
345 \\
245 \\
384 \\
254 \\
112 \\
464 \\
426\end{array}$ & $\begin{array}{r}726 \\
267 \\
75 \\
506 \\
451 \\
1143 \\
232 \\
350 \\
384 \\
60 \\
75 \\
82 \\
441 \\
354 \\
131 \\
467 \\
283 \\
394 \\
662 \\
137 \\
281 \\
357\end{array}$ & $\begin{array}{r}65 \\
1 \\
12 \\
13 \\
43 \\
29 \\
2 \\
19 \\
10 \\
19 \\
19 \\
59 \\
5 \\
17 \\
5 \\
21 \\
43 \\
10 \\
10 \\
14 \\
7 \\
1\end{array}$ & $\begin{array}{r}69 \\
5 \\
23 \\
18 \\
4 \\
166 \\
19 \\
23 \\
37 \\
38 \\
20 \\
16 \\
5 \\
24 \\
41 \\
7 \\
34 \\
13 \\
188 \\
40 \\
35 \\
17\end{array}$ \\
\hline
\end{tabular}

Table 1. Parameters of specimens and the defect diameters measured and predicted and their errors

$D_{0}$ : original wire diameter, $D_{1}$ : metallographic observation, $D_{2 a}, E_{2 a}, D_{2 b}, E_{2 b}$ : predictions (ultrasonic measured and calculated from eqns (6) and (7)). 
slightly with density when the radius was about $300 \mu \mathrm{m}$. At about $100 \mu \mathrm{m}$, on the contrary, the errors were reduced with increasing density. This may be explained by a combination of two factors: the errors from the residual stress region $\left(f_{1}\right)$ and the unavoidable artificial destruction during processing of the specimens $\left(f_{2}\right) . f_{1}$ is about proportional to the square of the wire diameter $(D)$ and the linear shrinkage of the matrix $(\delta)$. $\delta$ can be established from Fig. 2. $f_{2}$ decreased as the shrinkage increased. They can be expressed as follows:

$$
\begin{gathered}
f_{1}=A D^{2} \delta \\
f_{2}=B\left(\delta_{0}-\delta\right),
\end{gathered}
$$

and so the error $E=\frac{f_{1}+f_{2}}{D}$, where $A, B$ are constants. From Fig. 5, we assume that at $D=500,300$ and $100 \mu \mathrm{m}$ the deviations of the error $(\mathrm{d} E / \mathrm{d} \delta)$ are constants, and that they are $m, 0$ and $n$. From this assumption and eqns (8) and (9), we can obtain that $m / n \approx-0.4$. This is in agreement with the experimental data value of -0.32 (see Fig. 5). This means, although the scattering of the experimental errors is serious because the plane-wave theories are less suitable under small defect conditions, the

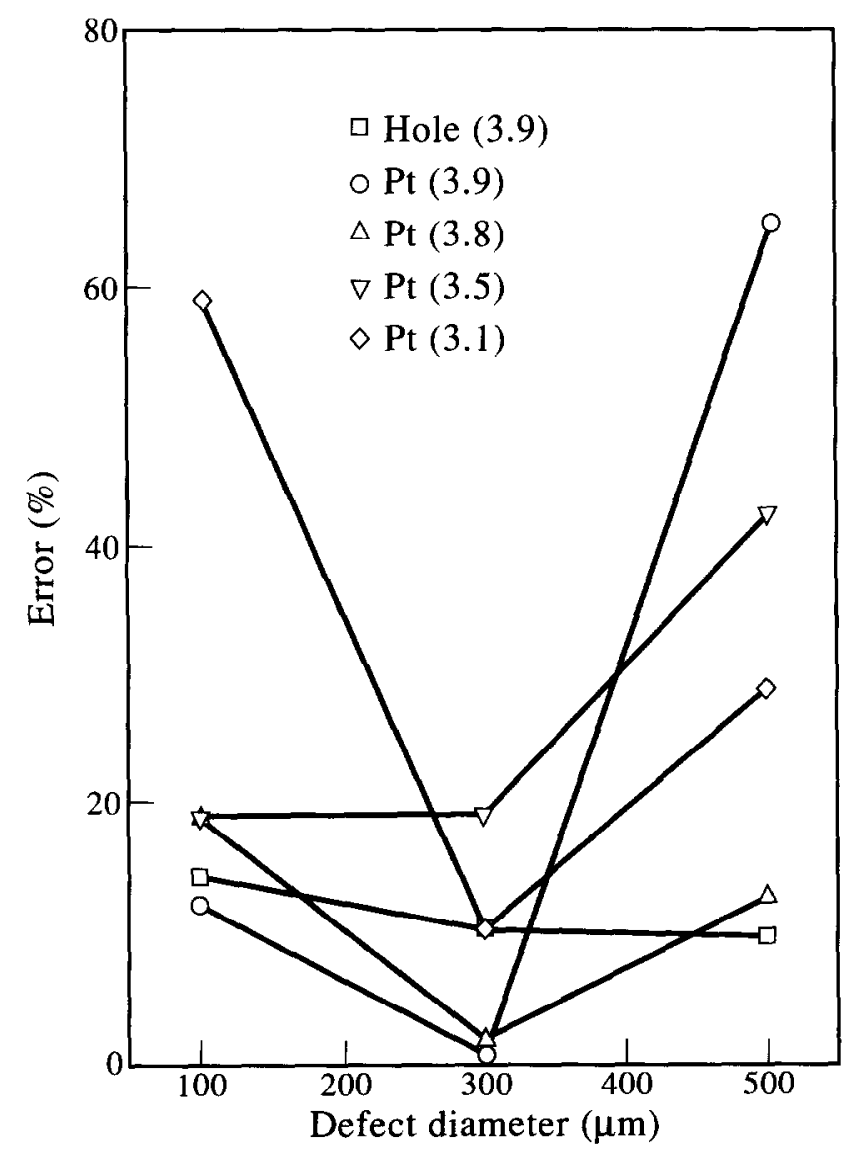

Fig. 4. The correlation between the error and the defect diameter. (...) bulk density of specimen, $\mathrm{g} / \mathrm{cm}^{3}$. trend of the course of errors is as predicted. It must be noted that the assumption $\frac{\mathrm{d} E}{\mathrm{~d} \delta} \simeq$ const. is a rough estimate. The data in Fig. 5 suggest to us that the discontinuous location of the powder size distribution caused by two-step formation of the green cake could be eliminated when the density was higher than $3.5 \mathrm{~g} / \mathrm{cm}^{3}$; in other words, after sintering at temperatures higher than $1300^{\circ} \mathrm{C}$ for $2 \mathrm{~h}$, the optimal density for the ultrasonic testing was $3.8 \mathrm{~g} / \mathrm{cm}^{3}$. Now we consider the " $C$-curve" in Fig. 4. With deviation of the error to the diameter $\left.\frac{\mathrm{d} E}{\mathrm{~d} D}\right|_{D+D_{0}}=0$, the equation

$$
D_{0}=\sqrt{\frac{B\left(\delta_{0}-\delta\right)}{A \delta}}
$$

is obtained, where $D_{0}$ is the optimal defect diameter on which the error is a minimum. $A$ and $B$ are defined as in eqns (8) and (9). We obtain $D_{0}=72,106,193$ and $348 \mu \mathrm{m}$ for different densities $\left(3.9,3.8,3.5\right.$ and $\left.3.1 \mathrm{~g} / \mathrm{cm}^{3}\right)$, sintered at different temperatures $\left(1550,1450,1350\right.$ and $\left.1250^{\circ} \mathrm{C}\right)$. From Fig. 4 the tendency shows that the optimal diameter of the minimum values of errors for ultrasonic testing decrease as the density increases. The correlation of eqn (10) and the experimental values fitted in Fig. 4 is shown in Fig. 6. Figure 7 shows the correlation between the error and the platinum

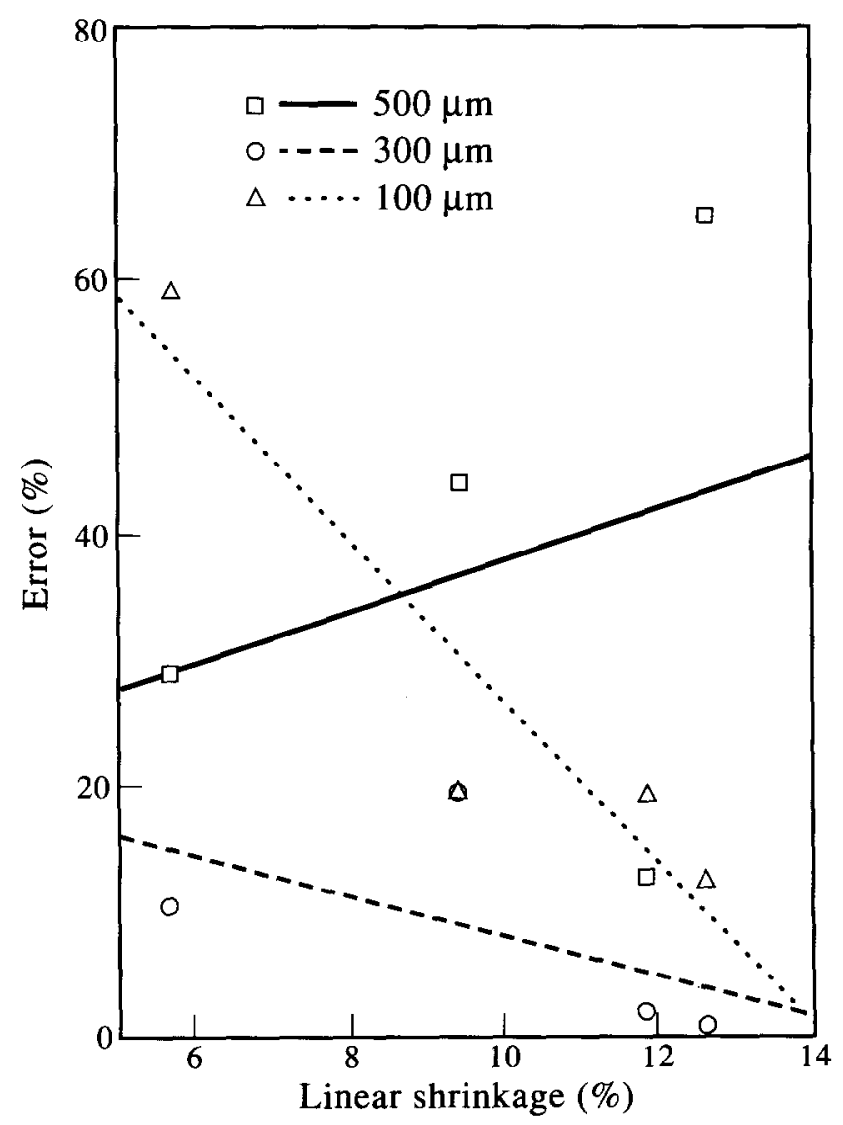

Fig. 5. The correlation between the error and the linear shrinkage. 


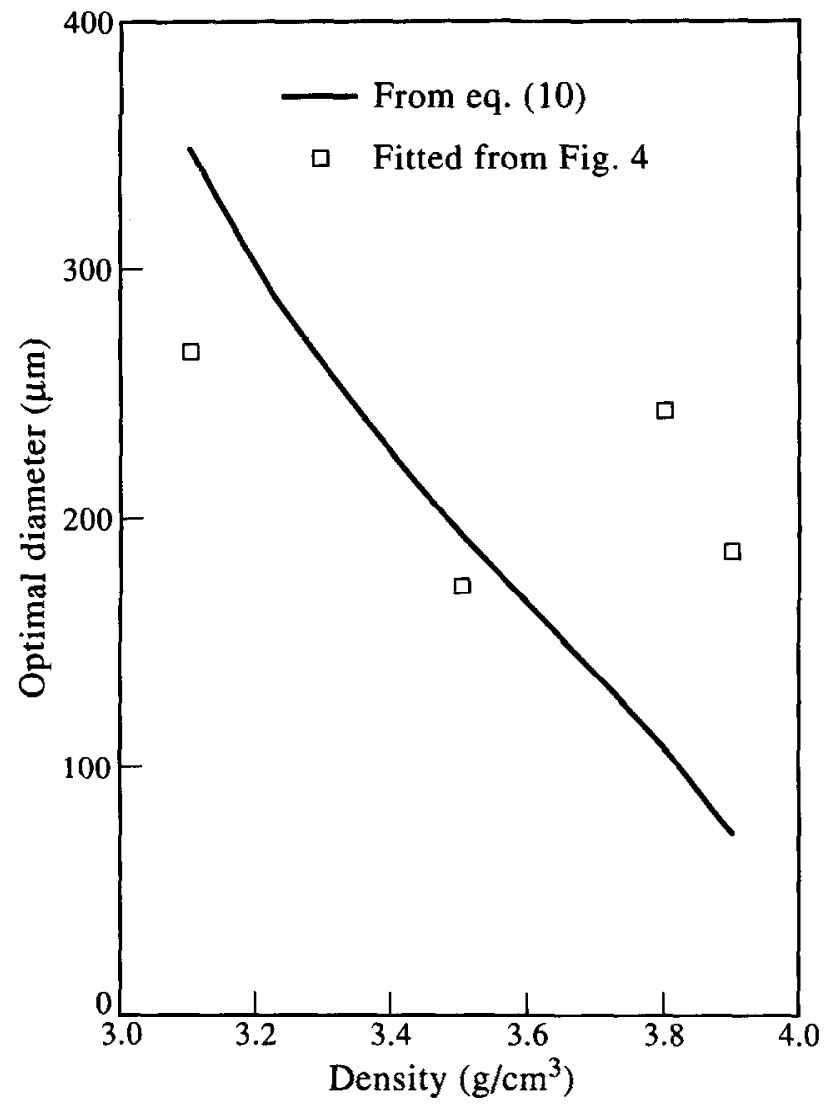

Fig. 6. The correlation between the optimal diameter and the density.

wire length with a diameter of $500 \mu \mathrm{m}$. The error was reduced to $2 \%$ when the length was $10 \mathrm{~mm}$. Since the transducer diameter was $7 \mathrm{~mm}$, eqn (3) had to be taken into consideration when the wire length was shorter than $7 \mathrm{~mm}$. This may have introduced more errors into the theoretical model. The total crror of eqn (3) was about $6 \Delta L$ when the error of the length was $\Delta L$. The experimental error in measuring the length was $5 \%$, and the total error was about $30 \%$. This agrees with the difference of the average values of two regions, 33.8 (see dotted lines in Fig. 7, 42.9 for $L<7 \mathrm{~mm}$ and 9.1 for $L>7 \mathrm{~mm}$ ).

\section{CONCLUSIONS}

1. The prediction of defect diameters using the equations which describe briefly each phenomenon involved in wave propagation in an alumina bulk containing a cylinder-like defect was reliable, and the error was tolerably smaller than $65 \%$ when the defect diameter was in the range $500-100 \mu \mathrm{m}$.

2. Correlations between the error and the parameters, diameter, density, etc., have been found and explained well by introducing some simple sintering concepts. The optimal density

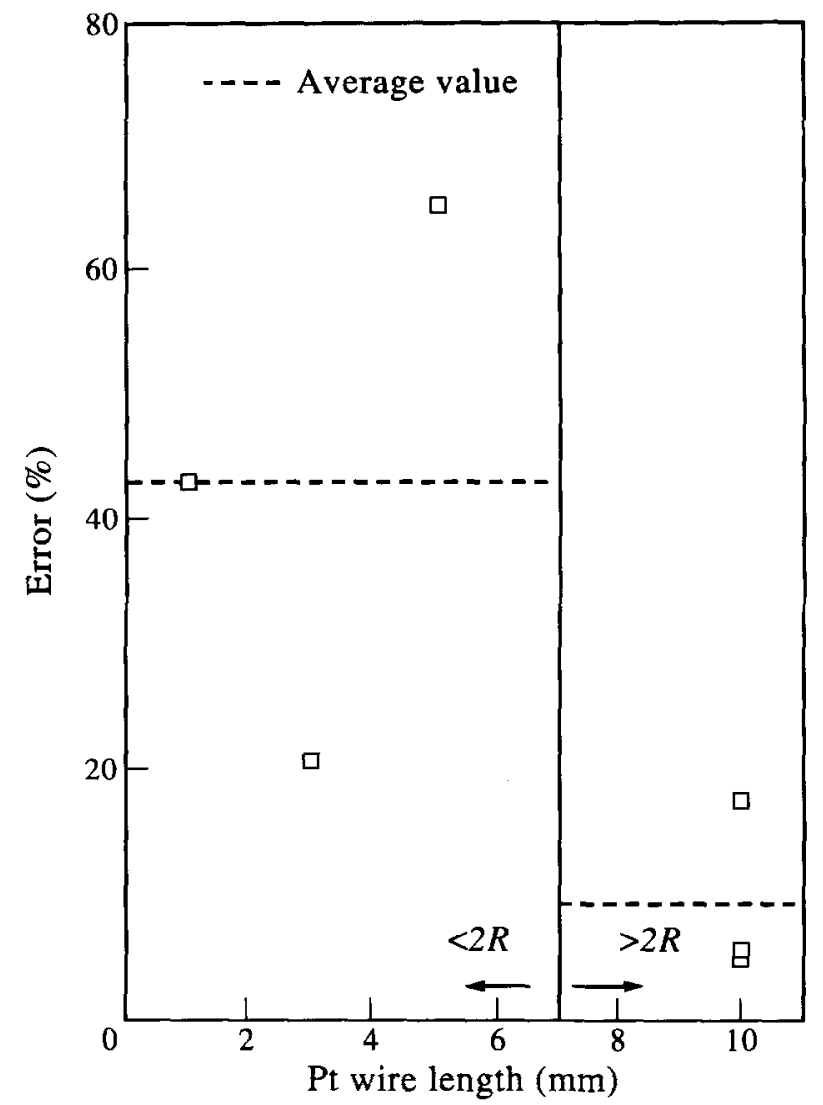

Fig. 7. The correlation between the error and the wire length. $R$ is the transducer radius.

for ultrasonic testing specimen was $3.8 \mathrm{~g} / \mathrm{cm}^{3}$ (sintered at $1450^{\circ} \mathrm{C}$ for $2 \mathrm{~h}$ ), and the obtained correlation between the density and the defect diameter on which the best accuracy was approximately linear.

3. The theoretical error found by introducing the factor of length explained well the error difference between the two defect length regions separated by $7 \mathrm{~mm}$.

\section{REFERENCES}

1. ELLIGSON, W. A., ROBERTS, R. A., ACKERMAN, J. L., SAWICKA, B. D., GRONEMEYER, S. \& KRITZ, J., Recent developments in nondestructive evaluation for structure ceramics. Int. Adv. in Nondestructive Test., 13 (1987) 267-294.

2. DAVIDGE, R. W., Defects in ceramics - the targets for NDT. Brit. Ceram. Trans. J., 88 (1989) 113-116.

3. KINO, G. S., The application of reciprocity theory to scattering of acoustic waves by flaws. J. Appl. Phys., 49(6) (1978) 3190-3199.

4. KHURI-YAKUB, B. T., KINO, G. S. \& EVANS, A. G., Acoustic surface wave measurements of surface cracks in ceramics. J. Am. Ceram. Soc., 63(1) (1980) 65-71.

5. HEFETZ, M. \& ROKHLIN, S. I., Thermal shock damage assessment in ceramics using ultrasonic waves. $J$. Am. Ceram. Soc., 75(7) (1992) 1839-1845.

6. PENNINGS, C. M. \& GRELLNER, W., Precise nondestructive determination of the density of porous ceramics. J. Am. Ceram. Soc., 71(7) (1989) 1268-1279. 
7. DANILOV, N., Calculation of the attenuation coefficient of elastic waves in scattering in polycrystalline media. Trans. from Defectoskopiya, 8 (1989) 18-23.

8. VOPILKIN, A.Kh., Methods of type recognition and measurement of defect dimensions in ultrasonic inspection (A review). Soviet J. Nondestructive Testing, (1990) 1-18.
9. ZHANG, Q., MA, T. \& LIN, S., Detection of defects in ceramic materials by ultrasonic technique. J. Inorg. Mater., 2(4) (1987) 354-362.

10. VARY, A., Correlations among ultrasonic propagation factors and fracture toughness properties of metallic materials. Mater. Eval., 36(7) (1978) 55-64. 